\title{
Em termos romanos: Res publica, história e constituição na historiografia do pensamento político e na historiografia institucional contemporâneas
}

\author{
Márlio Aguiar' \\ Tiago Bahia Losso ${ }^{2}$
}

\section{Resumo}

Desde que o neorrepublicanismo incluiu pensadores romanos e seus leitores modernos entre as fontes relevantes para o debate da Teoria Política, nota-se um interesse renovado pelas fontes romanas como elementos para enriquecer o debate contemporâneo da teoria política e também reavaliar a influência romana entre os modernos. Se de início seus autores enfatizavam a contribuição romana às tradições políticas modernas, defende-se que, em anos recentes, é possível verificar uma vasta produção voltada ao pensamento político dos romanos propriamente ditos, o que chamamos de "roman turn". Este artigo tem por objetivo contextualizar e delinear as características metodológicas dessa "virada romana". Para tal, o texto está dividido em duas seções: a primeira analisa a historiografia do pensamento político propriamente dita, após o impulso do contextualismo da Escola de Cambridge; a segunda seção se dedica à história do direito e, mais especificamente, aos rumos recentes da historiografia institucional ou constitucional.

Palavras-chave: História das instituições. História das ideias. Teoria e História da Historiografia.

I Doutor em Direito Civil (Direito Romano) pela Universidade de São Paulo (USP). Pesquisador do Grupo de Estudos em Latim e Fontes de Direito Romano: Ius Dicere - Universidade Federal de Santa Catarina (UFSC). Currículo na Plataforma Lattes: http://lattes.cnpq.br/273978335 I994899. ID ORCID: https://orcid.org/0000-00029319-7783. Perfil Academia: https://direito.academia.edu/MarlioAguiar. Contato: marlio.aguiar@gmail.com

2 Doutor em Ciências Sociais pela Universidade Estadual de Campinas (UNICAMP). Professor Associado do Departamento de Sociologia e Ciência Política da Universidade Federal de Santa Catarina (UFSC). Pesquisador do Núcleo de Estudos do Pensamento Político (NEPP/UFSC). Currículo na Plataforma Lattes: http://lattes.cnpq. br/697046 1043273233. ID ORCID: https://orcid.org/0000-0002-093I-I7I6. Contato: tiagolosso@gmail.com

\section{$(\mathrm{cc}) \mathrm{Br}$}

Direito autoral e licença de uso: Este artigo está licenciado sob uma Licença Creative Commons. Com essa licença você pode compartilhar, adaptar, para qualquer fim, desde que atribua a autoria da obra, forneça um link para a licença, e indicar se foram feitas alterações. 


\section{Introdução}

Ao acrescentar uma nota metodológica ao volume em que publica as aulas que ministrou ao ocupar o posto de regius professor em história moderna em Cambridge, Quentin Skinner aponta qual deve ser a tarefa do historiador do pensamento: "[...] agir como um tipo de arqueólogo, trazendo de volta para a superfície tesouros intelectuais enterrados, limpando sua poeira e possibilitando-nos reconsiderar o que pensamos deles" (SKINNER 1999, p. 90). Junto a outros historiadores, Skinner empreendeu sua parte nesse esforço arqueológico, apontando as raízes romanas do pensamento político do Renascimento. Acreditando estar tirando o pó de uma tradição praticamente abandonada pelos estudiosos da política desde meados do século XIX, Skinner apresenta aos leitores de fins do século XX uma tradição intelectual - nomeada por ele de neorromana - fundamental para a compreensão dos debates que forjaram o pensamento político moderno. Se os historiadores de Cambridge investigaram o pensamento político do início da Modernidade, insistindo na raiz romana da referida tradição, acabaram por ensejar um esforço de retirar o pó das relíquias intelectuais da Roma republicana. Este esforço se traduziu em tentar recuperar o significado dos escritos dos autores romanos dos estertores da república em seus próprios termos, lidando com interpretaçóes que relegaram os escritores romanos a um canto empoeirado da Teoria Política, como precisamente indicado por um crítico contemporâneo (HAMMER, 2014). Sheldon Wolin expressava bem o fenômeno nos anos 1960 com o seguinte comentário: “[...] the student of political ideas must deal with a period notoriously lacking in great political thinkers" (2004 apud HAMMER 2014, p. 1).

Desde então, o interesse por Roma se tornou o produto do esforço de diferentes analistas contemporâneos que, de início - recuperando autores que teriam sido influenciados por Políbio, Cícero, Lívio, e Ulpiano -, acabaram abrindo caminho para uma inédita reavaliação dos escritos romanos; podemos dizer, on Roman terms. Como asseverou um comentador do fenômeno, "[...] if the last century belonged to Greek political thought, the current has begun on a more Latin note" (KAPUST, 2017, p. 705), e tal literatura especializada atesta a existência de um roman turn partilhado 
por vários campos do pensamento. $\mathrm{O}$ escopo deste artigo é o de apresentar contextualmente o processo de (re-) emergência da romanística, tanto na historiografia das ideias políticas quanto na história jurídica (constitucional e institucional), e como esses domínios passaram a se enriquecer mutuamente com cada vez mais vigor no último quartel do século XX.

O artigo é composto por duas outras seçôes e por nossas considerações finais. A primeira seção versa sobre a emergência de um interesse renovado por parte dos estudiosos da política pelo pensamento e instituições políticas da Roma republicana. Indica-se como o interesse de historiadores do pensamento político pelo contexto do renascimento italiano implicará em trazer, à consideração dos leitores contemporâneos, uma tradição de pensamento político que possui suas raízes em escritores dos estertores da Roma republicana, ensejando uma visada também renovada sobre o contexto intelectual de onde brota a teoria neorromana, utilizando-se o termo cunhado por Quentin Skinner.

A seção seguinte traça o quadro contextual no qual a historiografia jurídica romanista, particularmente sua vertente institucional ou constitucional, passou a compartilhar de preocupaçóes metodológicas similares. Para tanto, recompôs-se em um primeiro momento a fundação científica da historiografia constitucional na Escola Histórica Alemã do século XIX e suas características principais. Em seguida, evidencia-se a emergência de críticas que levaram a uma renovação epistemológica por volta da metade do século XX, fundadas na diretriz comum de integrar os elementos jurídico-institucionais do mundo romano num quadro mais amplo do pensamento político. Aponta-se a convergência dessa vertente renovada da historiografia constitucional com a literatura alinhavada na seção anterior, isto é, dos teóricos do Roman turn à historiografia do pensamento político mais ampla.

\section{Roman Turn na Teoria Política}

Náo se trata propriamente de uma novidade o reaparecimento de elementos do pensamento romano nos debates contemporâneos da Teoria Política. Desde os trabalhos de Quentin Skinner e Philip Pettit, argumentos apoiados em autores da Roma republicana voltaram à pauta e se 
tornaram comuns mesmo entre autores não vinculados à tradição republicana de pensamento político. Doutro lado, convergiu com tal interesse a disseminação dos aportes teórico-metodológicos do contextualismo de Cambridge, da virada linguística e da história dos conceitos, instigando pesquisas renovadas sobre a história do pensamento.

Especificamente no caso dos aportes teórico-metodológicos, deve ser ressaltado que a sugestão desta abordagem é essencialmente contextualista. De forma geral, os historiadores de Cambridge sugerem ser necessária a recuperação dos contextos em que escritos sobre a política são articulados. Acessar o contexto social e, especialmente, o contexto intelectual que que determinada peça foi composta é o caminho mais adequado para compreender seu significado. No caso de Skinner, advoga-se pela recuperação das intenções autorais por meio da interpretação de peças literárias, exigindo que o historiador do pensamento se pergunte o que determinado autor estava fazendo ao escrever (SKINNER 1996, p. 13).

$\mathrm{O}$ republican revival inicialmente gerou um debate orbitando um conceito de liberdade (libertas) pretensamente singular, diverso do modelo liberal, tendo por valor a não dominação. Segundo os neorrepublicanos, tal ideia republicana de liberdade e a própria tradição republicana "begins in classical Rome, finding expression in the work of Polybius, Cicero and Livy" (PETTIT, 2016, p. 157), e se manteve viva pela leitura desses escritores entre autores modernos ${ }^{3}$, antes do estabelecimento da formulação bipartida de liberdade positiva (dos antigos, ligadas à participação política ativa como fim mais elevado humano e ao self-mastery) e negativa (dos modernos, de viés liberal, como não interferência) indicada por Benjamin Constant e refinada teoricamente por Isaiah Berlin (BERLIN, 2002).

Philip Pettit é o autor mais relevante para identificar a emergência contemporânea de uma teoria política calcada em fontes romanas e renascentistas. Suas contribuiçóes de maior fôlego estão em Republicanism: A Theory of Freedom and Government (PETTIT, 1997) e em On the People's Terms: A Republican Theory and Model of Democracy (PETTIT, 2012).

3 A ilustrar a densidade dessa vertente de discussão na teoria política e historiografia contemporânea: Pettit, 1997, 2012; Skinner, 1999; Viroli, 2002; Kapust, 2004; Labord e Maynor, 2008; McCormick, 201 I. 
Ao patrocinar este retorno ao republicanismo na teoria política, Pettit indica três ideias nucleares de uma tradição de pensamento que remontaria ao pensamento e às instituiçóes romanas: um conceito específico de liberdade, apresentado em termos de não dominação; a vigência de um arranjo comumente nomeado constituição "mista" (PETTIT, 1997, p. 7s); e a necessidade da manutenção de uma cidadania contestatória, manifesta não somente em mecanismos de vocalização mas também de responsividade governamental para demandas populares (PETTIT, 2012, p. 5-6).

Movida pelos pilares da liberdade como não dominação, da constituição mista e da democracia contestatória, a tradição republicana disputou espaço com tradiçóes outras, sobretudo o liberalismo e o utilitarismo, insistindo em se inserir na herança da antiga Urbe. Nas palavras de Nadia Urbinati (2012, p. 607); "in the last decade, the neo-roman republican theory of freedom as non-domination has acquired a leading status in political science and redesigned the geography of political studies".

Desde então, o campo de estudos voltado ao pensamento romano se alargou para além de sua origem-estopim recente no debate acerca do conceito de libertas. O roman revival, de fato, recebeu impulso das discussóes levantadas pelos neorrepublicanos, mas representa hoje uma tendência que, por si só, atravessa os mais diversos campos disciplinares e correntes de pensamento. Uma lista náo exaustiva em torno das recentes pesquisas inclui, além do conceito de libertas e estudos sobre autores específicos da tradição, temas como a persuasão retórica no espaço público (KAPUST, 2011; CONNOLLY, 2007); as relaçóes com o liberalismo, o comunitarismo, o socialismo e o constitucionalismo (HABERMAS, 1994; PINZANI 2007); a legitimação política e a fundamentação da autoridade pública através do direito em diferentes formulaçóes republicanas na história (SKINNER; BOURKE 2016); a configuração juspublicística da comunidade política (BESSON; MARTI, 2010); a investigação de outros conceitos-chave da tradição como populus ou res publica (SCHOFIELD, 1995).

$\mathrm{O}$ acesso aos escritores romanos, partindo do interesse da teoria política contemporânea pela tradição republicana de vertente romana, em parte, é resultado de uma articulação mais ampla entre teoria política e 
história do pensamento político. A relação entre os trabalhos dos mais destacados participantes do debate indica os contornos fundamentais de um estilo marcadamente histórico de reflexão sobre a política. Skinner sugere que, enquanto o historiador retira a poeira de tradiçóes intelectuais abandonadas por geraçóes anteriores, está fornecendo insumos para a reflexão teórica, esta que pode, então, contar com um vocabulário alargado para suas considerações sobre os dilemas contemporâneos (SKINNER, 1999, p. 89-90). A teoria política, por sua vez, forneceria ao historiador das ideias políticas ferramentas para lidar com seu objeto de estudos, ao cultivar um vocabulário sobre o mundo da política ${ }^{4}$. A ênfase da análise de Pettit não recai sobre as fundaçóes históricas do republicanismo, mas, sim, na estrutura conceitual da tradição para construir argumentos normativos em seu favor. Ainda assim, como Skinner, considera os antigos escritores romanos a raiz da tradição (PETTIT, 1997; KAPUST, 2011), razão para expor sinteticamente as linhas gerais descritas pelos neorrepublicanos e apropriadas pelo debate mais amplo.

A tradição republicana de pensamento político que remonta a Roma teria em três autores seu marco, todos escrevendo na segunda metade do século I a.C.: Marco Túlio Cícero, Caio Salústio Crispo e Tito Lívio. Um elemento comum aos autores mencionados é a recorrente referência ao ineditismo da constituição romana, vista como um balanço perfeito entre os princípios constitucionais náo degenerados, a qual, em seus escritos, emerge como uma característica fundamental para se compreender a realidade política de Roma. A discussão sobre tipos constitucionais remonta ao século de Péricles e foi introduzida em Roma por Políbio ${ }^{5}$. O historiador estabelece que a compreensão última do poderio romano depende de uma criteriosa análise da constituição da urbe, algo já anunciado nas linhas iniciais de sua História (Políbio, História I, 1), tornando o tema um dos princípios de sua perspectiva historiográfica (SEBASTIANI, 2006, p. 30). Políbio apresenta, como destaca McGing (2010, p. 169), a primeira tentativa de aplicar a teoria política grega às estruturas de governo de Roma, "[...] and the only attempt by someone who was technically an outsider to understand Roman success in terms of its constitutional excellence".

\footnotetext{
4 Sobre a relação entre história das ideias e teoria política, ver: Silva, 2009.

5 Para uma análise dos estudos sobre Políbio vide: Walbank, 2002, p. I-27.

6 Ver também: Hammer, 2014, p. 7-II.
} 
O historiador grego condensou suas consideraçôes sobre a constituição romana no sexto livro de sua História, mas já no trecho inicial pergunta "[...] quem seria tão inútil ou indolente a ponto de não desejar saber como e sob que espécie de constituiçáo os romanos conseguiram em menos de cinquenta e três anos submeter quase todo o mundo habitado ao seu governo exclusivo - fato nunca antes ocorrido?" (Políbio, História I, 1). Formulando a mesma pergunta no sexto livro, Políbio passa a discorrer sobre a constituiçáo romana, situando seu argumento em termos correntes no Mediterrâneo antigo. Primeiro, estabelece distinçóes entre diferentes tipos de governo da forma corrente desde Aristóteles: seis tipos virtuosos (monarquia, aristocracia, democracia) e seus tipos de degenerados (autocracia, oligarquia, oclocracia) (Políbio, História VI, 3-4). Em seguida, apresenta uma dinâmica de ascensão e queda de tipos constitucionais, numa alternância cíclica (anacyclosis) entre os tipos degenerados e virtuosos de

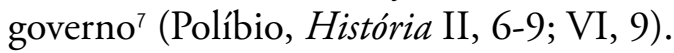

As sucessóes seriam engendradas pelo perigo inerente a cada tipo constitucional, na monarquia a tendência ao despotismo, na aristocracia à oligarquia e na democracia a inclinaçáo para a "selvageria e ao império da violência” (Políbio, História VI, 10). Neste mesmo trecho, Políbio elogia Licurgo por ter formado uma mistura táo boa que durou quatro séculos, acrescentando, no entanto, que os romanos chegaram aos mesmos efeitos não através do raciocínio (como o legislador espartano), “[...] mas graças às liçôes hauridas em muitos embates e dilemas, e escolhendo sempre o melhor à luz da experiência ganha em desastres [...]" (Políbio, História VI, 10).

A mistura constitucional alcançada em Roma, ainda segundo Políbio, era tal que "[...] a quem fixar a atenção no poder dos cônsules a constituição romana parecerá totalmente monárquica; a quem fixá-la no Senado ela mais parecerá aristocrática, e a quem a fixar no poder do povo ela parecerá claramente democrática" (Políbio, História VI, 11). Após escrutinar as prerrogativas das instituiçóes da constituição romana, Políbio afirma que é em momentos de crise, quando a abundância inclina os homens à indolência e ao descuido com o interesse público é que este

7 Para uma análise dos ciclos constitucionais, cf. McGing, 2010, p. I70s. 
arranjo mostra sua pertinência (Políbio, História VI, 18). Note-se que é a dinâmica entre diferentes locais de poder que, desde que de forma equilibrada, garante a vitalidade da constituição romana. No seu registro, Roma é o exemplo perfeito do bom governo conduzido por uma mistura constitucional de equilíbrio, singularmente baseada em um mecanismo de contenção do arbítrio obtido ao longo de muitas geraçôes. De maneira relativamente clara, em parte sistemática, Cícero e Lívio creditavam a esse desenho institucional ${ }^{8}$ a durabilidade da sua comunidade política, alargando a trilha aberta por Políbio.

Em Cícero, esse argumento é localizável em seu tratado De Re Publica. Não por acaso, escolheu como protagonista de seu diálogo um personagem que teve Políbio como companheiro e tutor, Cipiáo Emiliano. Este foi encarregado no diálogo de discorrer sobre a melhor forma de ordenar uma comunidade política em virtude de sua familiaridade com as teses gregas, mas Cícero o faz lembrar que seus interlocutores ouvirão alguém não "absolutamente inexperiente nas disciplinas dos Gregos" mas "muito mais instruído pela experiência e pelos preceitos domésticos do que pelas letras" (Cícero, República I, 36). Logo após definir o tema da exposição - a res publica (Cícero, República I, 39) - o personagem de Cícero afirma que toda República necessita de um "órgão de governo" para durar (Cícero, República I, 41). Segue, então, a mesma tipologia avançada por Políbio, discorrendo sobre governos justos e degenerados de um, alguns ou muitos (Cícero, República I, 42).

$\mathrm{Na}$ esteira de Políbio, Cícero inicialmente afirma ser a alternância entre tipos constitucionais inelutável e que cabe ao bom governante prever um percurso capaz de os moderar e de manter o ciclo sob alguma forma de guia. Ao final do primeiro livro, tendo Cipião concluído a discussão preliminar das teorias das formas de governo e da constituiçáo mista - pedindo escusas por ter soado em tom extremamente professoral ou filosófico -, o narrador diz a seus colegas que a discussão iria se voltar para algo muito

8 Os antigos não usavam o termo "constituição" no sentido hoje empregado para modelo constitucional. O termo constitutio em Cícero faz referência somente ao conjunto de arranjos institucionais formados historicamente (Cícero, República I, 4I; II, 37). 
mais familiar: a própria história de Roma9 (Cícero, República I, 70). No começo do livro segundo, Cipião confirma que a constituição romana não se formou a partir de um simples legislador ou de ideias fundantes num texto utópico como os de Platão, mas a partir de geraçóes e de um longo período de maturidade (Cícero, República II, 3). A história de Roma daria lugar então a "[...] um quarto tipo de constituição, que seja uma moderada mistura dos três que indiquei em primeiro lugar" (Cícero, República I, 45), apresentada através da memória de um discurso de Catâo, arquétipo da virtude republicana (Cícero, República II, 1-2) e, como destaca Hammer (2014), uma forma constitucional que simultaneamente impede a concentração de imperium nas mãos de uma só instituição ou homem, bem como salvaguarda a auctoritas senatorial e a libertas do povo romano.

A constituição romana era superior justamente por ter contado com a "experiência das coisas" e com "certo amadurecimento" (Cícero, República II, 2), tornando possível falar de suas características (e nelas se inspirar) sem ser necessário recorrer a criaçóes como "Sócrates em Platão" (Cícero, República II, 3). Este é o preâmbulo para a continuidade do segundo livro do tratado que conhecemos, dedicado, entáo, ao ato de narrar a história que conduziu Roma a seu desenho institucional. O livro segundo do tratado propóe uma história constitucional de Roma, não exatamente aos moldes da historiografia romana (especialmente da tradição analista). Tampouco se trata de uma narrativa de tipo ideal, e sim, como enfatiza Powell, uma história exemplar - algo explicado claramente em Cícero (República II, 64-66). O objetivo não é fornecer receitas que devem ser seguidas institucionalmente (nesse ponto o platônico Cícero diverge da posição do platonismo político), mas demonstrar historicamente ${ }^{10}$ algumas das questóes preditas pela teoria da constituição mista (POWELL, 2001, p. 29-30)."

9 Como enfatiza precisamente T. J. Cornell (200I, p. 43-45), o balanço entre a erudição (ou o aprendizado através dos livros, de caráter teórico), virtude intelectual mais tipicamente grega, e a "experiência prática”, a prática política romana, é um mote não apenas explícito do personagem escolhido por Cícero, mas da construção de todo o tratado filosófico.

10 As personagens da história de Roma são evocadas para dar exemplos de monarquia (Rômulo), Tirania (Tarquínio), Aristocracia (Brutus) (Cícero, República II, 5I), Oligarquia (os decênviros), Democracia (eventos históricos relevantes como a expulsão dos reis e as secessões da plebe) e, por fim, o alcance da constituição mista após 449 a.C. (Cícero, República II, 63).

II Ver também: Asmis, 2004, p. 584-586. 
Se Cícero alicerça de maneira clara a singularidade do equilíbrio da constituição mista, Lívio compôs uma narrativa tendo o surgimento gradual das instituiçóes romanas como um de seus eixos mais relevantes. Em sua História de Roma, Tito Lívio indica que, entre os séculos entre a fundação da cidade e a publicação das XII Tábuas, surgiram as instituições que criaram o equilíbrio louvado por Políbio. Quando os escritores elogiavam Roma, era para esta etapa de sua história que olhavam. Embora Lívio tenha narrado a construção de uma constituiçáo que manteria a liberdade para os romanos sem mencionar o termo constituição mista e enfatizando ainda mais do que Cícero o componente moral da comunidade política - vide Kapust (2011, p. 103-107); cf. Hammer (2014, p. 253-257), sua história foi enquadrada num argumento sobre a singularidade da constituição tipicamente romana, próximo de Políbio e Cícero, assentando uma das pedras de toque do republicanismo.

Lívio localiza a fundação de Roma em 753 a.C., e Rômulo se torna o primeiro rei da cidade, mas nunca teria governado autocraticamente. Suas primeiras decisôes indicam: a criação de regras comuns e a escolha de um conselho de patres que com ele governaria a nova cidade (Lívio, História I, 8). A cidade foi repartida em trinta cúrias e foram criadas as primeiras centúrias de cavaleiros, complexificando o exercício do poder e incluindo outros centros de autoridade no processo decisório (Lívio, História I, 13). Após reformulação na composição das centúrias de cavaleiros durante o reinado de Tarquínio Prisco (Lívio, História I, 36), foram criados os comitia centuriata nas reformas de Sérvio Túlio. Para Lívio "a mais considerável das obras realizadas em tempos de paz" ocorreu quando a população foi dividida em classes e centúrias. As centúrias incluíram a população na dinâmica do governo, mesmo que com a clara preferência dada aos que, de acordo com o censo, possuíssem maior quantidade de recursos (Lívio, História I, 43).

Lívio sugere o encontro da cidade com a liberdade coincide com a expulsão dos reis. A primeira ocorrência se dá após a morte de Rômulo, momento em que todos desejavam ainda um regime monárquico, "pois ainda não haviam provado a doçura da liberdade” (Lívio, História I, 17). Adiante, Lívio indica que Sérvio Túlio pretendia abrir mão de determinadas prerrogativas reais que possuía, mas seu assassinato o impediu de 
concretizar o seu "projeto de libertar a pátria” (Lívio, História I, 48). Quando Bruto lidera a revolta que expulsa o último rei, Lívio o nomeia, não à toa, liberator urbis, o "libertador da cidade" (Lívio, História I, 60).

Após a expulsão do rei, foi instituída uma nova magistratura: o consulado; e Lívio passa então a narrar: "[...] os feitos que o povo romano, livre a partir de então, empreendeu tanto na guerra quanto na paz, sob o governo de magistrados eleitos anualmente e sob a autoridade de leis superiores à autoridade dos homens" (Lívio, História II, 1). No entanto, nota, "[...] se a liberdade se há de fixar nessa época, foi antes porque a duração do mandato consular se limitou a um ano e não porque se restringiu sob qualquer aspecto o poder real" (Lívio, História II, 1). Quando o consulado é instalado, portanto, duas instituiçóes fundamentais da constituição mista romana estavam criadas, mesmo que nenhuma tenha sido precedida de planejamento prévio, e sim resultados das circunstâncias. Para compor o quadro louvado por Políbio mais duas iniciativas seriam decisivas: o estabelecimento de uma magistratura aos plebeus e o estabelecimento de normas de conhecimento público e aplicação uniforme. Em ambos os casos, foram frutos de conflitos políticos e mecanismos para impedir o exercício imoderado do poder.

A criação do tribunato da plebe é um processo detonado pela revolta gerada entre o povo contra a escravidáo por dívidas, vivamente descrita por Lívio na sequência em que um ancião maltrapilho é reconhecido no Fórum como um cidadão romano, reduzido à indigência e posterior escravização mesmo tendo dedicado seus melhores esforços à Roma (Lívio, História II, 23). Uma série de atritos entre plebe e patriciado culmina com a retirada da plebe para o Monte Sacro, sendo convencida a voltar para a cidade para sua defesa apenas após a criação de uma magistratura voltada à defesa dos plebeus, os tribunos da plebe, considerados sacros e invioláveis (Lívio, História II, 33). Protegida dos cônsules, ainda parecia à plebe que o patriciado dominava a cidade, já que suas iniciativas políticas eram constantemente obstadas. Como iniciativa de um tribuno, foi entáo decidido que, se o patriciado náo aceitava as leis propostas pela plebe, que fosse então criada uma comissão de patrícios e plebeus “[...] com o encargo de redigir leis úteis às duas ordens e capazes de assegurar a igualdade e a liberdade" (Lívio, História III, 31). 
Foi enviada uma delegação à Grécia, encarregada de procurar inspiração para o estabelecimento de leis nestes termos. Quando do retorno desta legação foram escolhidos dez magistrados encarregados de redigir a futuramente conhecida Lei da XII Tábuas (Lívio, História III, 31-33). Ao longo de dois anos em que os decênviros, desfrutando de poderes absolutos, mostraram a brutalidade do exercício incontido do poder - culminando na dramática morte de Virgínia - as leis foram finalizadas e, depois de demitidos os decênviros, as instituiçóes políticas tornaram a funcionar (Lívio, História III, 57).

A liberdade - "doce”, de acordo com Lívio - fora alcançada em Roma através do estabelecimento de mecanismos que impediram o exercício imoderado do poder. Nisso consistia o segredo das qualidades da constituição mista secretada pela história da cidade. Não se tratava de um determinado tipo de governo ou governante. Patrícios e plebeus são capazes de atos virtuosos e nefastos ao longo dos trezentos anos que separam a fundação da cidade da estabilidade republicana desfrutada entre o fim do conflito das ordens e a queda de Cartago. O que garantiu a prosperidade e o desfrute da liberdade resultaria de um fato: qualquer tentativa de exercício arbitrário do poder seria coibida, ou melhor, temperada, através de outras fontes de autoridade. Ilustração disso é a decisão tomada no âmbito dos acordos feitos após a demissão dos decênviros, de se sancionar uma "[...] nova lei que proibia a criação de qualquer magistratura sem apelação" (Lívio, História III, 55). Os arcana imperii de Roma estavam nas instituiçóes.

A “constituição" romana, celebrada pelos escritores romanos e tida como fonte de inspiração para pensadores vinculados à tradição republicana, era formada por um complexo mosaico de magistraturas, prerrogativas e procedimentos conformados pelas leis, pelo direito e pelos costumes. Compreender e atribuir significado às fontes históricas de que dispomos significa, na formulaçáo de um de seus estudiosos, em recuperar uma gramática específica e, partindo da linguagem então articulada, compreender como as instituiçóes políticas romanas eram legitimadas, criadas e estabilizadas. O historiador das ideias interessado na realidade política da Roma republicana precisa atuar como um intérprete: "One might even formulate the ambitious ultimate aim of this project in the classic Geertzian 
terms: we have to learn how to read this 'culture' of the populus Romanus [...]" (HÖLKESKAMP, 2010, p. 53).

Localizar os atos políticos dos romanos, suspensos em teias de significados que eles mesmos teceram - seguindo os termos de Geertz ([1973] 2019), retomado infra, exige assumir que as categorias modernas e contemporâneas não são suficientes para tal empreitada. Recuperar a gramática política na qual os escritores romanos elaboraram os elogios ao seu modelo constitucional é necessariamente uma tarefa que precisa compreender a profunda inter-relaçáo entre direito, leis e costumes, pois a política romana se expressava através dessas três dimensões imbrincadas. A pesquisa contemporânea tem dedicado esforço a essa empreitada, e a seção seguinte pretende apresentar um panorama desse empreendimento de compreender a política em seus próprios termos através dos diálogos com outro campo de saber.

\section{A história do direito, a historiografia constitucional/ institucional e o Roman Turn}

Nesta seção temos por foco a historiografia institucional ${ }^{12}$ romanista e, mais precisamente, as mutaçôes metodológicas ocorridas nessa senda desde o século XIX até o presente. Por caminhos teóricos distintos dos apontados na seção anterior para o Roman Turn na teoria política e os desenvolvimentos da história do pensamento político, a historiografia constitucional conheceu sua própria virada metodológica na segunda metade do século XX. Buscamos, a seguir, demonstrar como as questóes que tal historiografia passou priorizar, bem como as soluçôes metodológicas adotadas, convergiram nas últimas décadas com a historiografia das ideias políticas.

A historiografia institucional a respeito da Antiguidade romana deita suas raízes no ramo Romanístico da Escola Histórica Alemã ${ }^{13}$. Entre os pioneiros podemos destacar Barthold George Niebuhr (1776-1831), que dedicou significativo espaço de sua História Romana (Römische Geschichte),

12 Usamos "história institucional" e "constitucional" como termos sinônimos, relacionados com a afirmação da história do direito no século XIX.

13 Sobre o contexto intelectual da Escola Histórica Iggers, I983, p. 90-I23. Wieacker, 20I0, p. 397-429, 475-49I. 
publicada entre 1811 e 1832, a uma análise das instituições políticas romanas; Joseph Rubino (1799-1864), talvez o primeiro autor a nomear uma obra do gênero com suas Investigaçóes sobre a constituição romana e a história (Untersuchungen über römische Verfassung und Geschichte), em 1839; e ainda Wilhelm Ihne (1821-1902), que lançou, em 1853, suas Investigaçóes no campo da história constitucional romana (Forschungen auf dem Gebiet der römischen Verfassungsgeschichte).

Foi, no entanto, Theodor Mommsen (1817-1903) quem estabeleceu as bases do mais sistemático tratamento da história institucional romana. Mais precisamente, optou Mommsen por intitular sua obra não como uma história constitucional, mas uma história do direito do Estado ou ainda uma história do direito público ${ }^{14}$. Foi assim que, entre 1871 e 1888 , já amplamente conhecido por sua História Romana (1853-1856), Mommsen publicou os três volumes da História do Direito Público Romano (Römisches Staatsrecht), seguida, em 1893, de um Sumário da História do Direito Público Romano (Abriss des Römisches Staatsrecht).

Inserido no período intelectual de efervescência da juspublicística germânica, a distinção da obra consistia em não apenas descrever o "Estado" romano e decompô-lo em seus elementos fundamentais, mas analisá-lo como um conjunto formal de regras ou, mais especificamente, um sistema coerente de normas do Estado (Staats-und Rechtsordnung) ${ }^{15}$, como a ciência jurídica alemã pretendia realizar com o Estado moderno. Se até então a história constitucional (Verfassungsgeschichte) e o próprio direito público (Staatsrecht) eram tratados como ramos derivados respectivamente da história política e da teoria do Estado (Staatslehre), coube a Mommsen e seus discípulos emancipá-las como ramos científicos autônomos, inclusive na investigação historiográfica. A reflexão sobre os órgáos políticos do mundo romano se tornava definitivamente assim parte do território da História do Direito.

Foi também a partir de Mommsen que a tripartição magistraturas/ Senado/assembleias se tornou a chave-interpretativa mainstream de toda a

14 Quanto às implicações da distinção entre Verfassungs- e Staatsrecht, ver: Murkens, 2007.

15 Mommsen, 187I-1888, I, p. 6s. 
pesquisa histórica voltada às instituições políticas e aos conceitos jurídicos da Roma antiga. A historiografia constitucional romana, para utilizar a formulação de Thomas Kuhn, entrou em um período de estabilização do paradigma proposto por Mommsen, formando uma ciência normal. Com os limites inerentes a qualquer resumo, poderíamos definir as características da historiografia constitucional a partir de eixos comuns: i- pressuposto de que as instituiçóes políticas, em qualquer sociedade histórica, tem propensão interna à formação de um ente abstrato maior, o Estado, com um aparelho normativo próprio na forma de um sistema ${ }^{16}$; ii- tem por assente a separação ao mesmo tempo conceitual e prática entre Estado e Sociedade, ou colocada em outros termos, entre realidade social e institucional; iii- orientação heurística para a busca de fontes ligadas às convenções, arranjos e/ou acordos que dão origem e forma às instituiçóes públicas, i.e. aquelas que constituem a comunidade jurídico-política; iv- que a matéria da investigação institucional é autônoma e devia se orientar antes pelas características das instituiçóes, sem estar presa à mesma narrativa histórica que rege a história política ou social ${ }^{17} ; \mathrm{v}$ - separação dogmática entre direito público e direito privado, reservando a história da jurisprudência romana majoritariamente ao domínio dos privatistas e a história institucional aos publicistas/constitucionalistas ${ }^{18}$.

Assumindo aquelas vigas mestras, as investigações de antanho buscavam lapidar os temas pesquisados (características, funções, e poderes das diversas autoridades públicas, e as regras formativas das instituiçóes em particular); integralizar um maior número de fontes ou responder quebra-cabeças pontuais, de modo a aumentar a precisão da compreensão do Staatsrecht novecentista, mas com interesse diminuto em redefinir conceitos operacionais; construir metodologias ou propor novas interpretaçóes a parcelas daquela narrativa histórica. $\mathrm{O}$ pressuposto normativo

I6 Em alemão Staatlichkeit, noção que toma o Estado como categoria anistórica e universal, característica visível na sistemática de romanistas, mas não ausente no ramo germanístico da Escola Histórica (BÖCKENFÖRDE, 20I2, p. 19-22).

17 Assim as investigações de história institucional romana se autonomizaram: enquanto os juristas se dedicaram àquelas, a história da agência política ficou a cargo de historiadores como F. Münzer e M. Gelzer.

18 O modelo de exposição em Staatsrecht seguia o plano da tratadística de direito privado, por uma progressão de tipo lógico-sistemática dos conceitos gerais (Grundbegriffe) às relações jurídicas concretas (MOMMSEN, 187 II888, I, p. viii-ix). 
positivista e a análise institucional-estatal se difundiram sob a autoridade de Mommsen, mesmo entre aqueles que criticavam os aspectos modernizantes de sua obra.

Não seria desmesurado dizer que a obra de Mommsen definiu a agenda lógico-sistemática da pesquisa da história constitucional romana até a metade do século XX (BÖCKENFÖRDE, 2012). A situação começou a se alterar a partir dos anos 1950 e mais visivelmente na década de 1960 . Alguns pesquisadores da área compartilhavam o julgamento do déficit de historicidade na reconstrução narrativa e na interpretação historiográfica a respeito do itinerário institucional romano, diagnosticando a origem desse problema na obsolescência da base teórica que no século XIX possibilitou a construçáo jurídica do Estado de Direito das democracias orientadas pelo liberalismo, pela socialdemocracia e pelo constitucionalismo.

Duas reaçóes distintas entraram no campo de possibilidades a partir da constatação crítica do déficit histórico e analítico da história constitucional. A primeira posição pode ser definida por uma percepção generalizada de ceticismo institucional e foi bem representada pelo ácido diagnóstico de Ronald Syme (1939, p. 15): "The Roman constitution was a screen and a sham". A mesma ideia foi expressa com vigor pelo historiador italiano Arnaldo Momigliano em uma conferência em 1966 na qual anunciou a celebração do fim da História do Direito como ramo autônomo de investigação histórica e a absorção integral daquela disciplina pela História Social. Para Momigliano, deviam ser reconhecidos como incompreensíveis os aspectos institucionais do Direito quando desacompanhados de apreciação do quadro de referências mais amplo de uma sociedade. Até mesmo a distinção entre uma análise técnico-dogmática e outra histórica do ius publicum se tornara, a seu ver, inútil (MOMIGLIANO, 1966, p. 101s.). Embora fosse compartilhada in abstrato a convicçáo de que a constituição deveria ser analisada em conjunto com o pano de fundo da estrutura social e das circunstâncias de mudança política ${ }^{19}$, produzir tal historiografia constitucional - na qual ambas, a estrutura jurídica e as forças sociais que

19 Mencione-se pars pro toto que já era diretriz da Escola Histórica reconstituir o Direito de sociedades passadas a partir de seus universos culturais: "die einheimischen Rechtsinstitute aus ihrem eigenen Geist heraus zu konstruieren” (GIERKE, 1903, p. 22). 
a pressionam, tenham o devido valor - estava longe de ser uma tarefa fácil. "Mommsen", concluiu Momigliano em outra ocasião, “[...] não pode ser substituído por ninguém menor do que Mommsen” (MOMIGLIANO, 1949 , p. 156) ${ }^{20}$.

No entanto, era naturalmente possível concordar com as críticas feitas à historiografia constitucional tradicional sem alcançar a conclusão metodologicamente mórbida de Momigliano e, por assim dizer, buscar um caminho mais construtivo ${ }^{21}$. Historiadores sociais também percebiam um entrelaçamento mais complexo entre a formação dos grupos político-sociais e o universo institucional (ALFÖLDY, 1989, p. 47). Tampouco é de surpreender que, entre os romanistas, a posição adotada tenha sido não a de rejeitar a literatura anterior ou os resultados até então obtidos, mas de reconhecer a necessidade de reformular as próprias perguntas ensejadoras de suas pesquisas. Levando em conta que a constituição romana náo podia mais ser assumida como um objeto abstrato, racional e previamente estruturado em normas estabelecidas pela vontade de um ente alheio à sociedade como o Estado, os historiadores e constitucionalistas a partir dos anos 1960 concordaram que precisariam entáo encontrar formas de caracterizar a complexa teia de instituiçóes dentro de seus contextos culturais e políticos concretos ${ }^{22}$.

Optamos por representar as obras do jurista italiano Francesco de Martino (1907-2002) e do historiador germânico Christian Meier (1929-) como exemplos das insatisfaçóes internas à área. Essas obras voltadas à história constitucional anteciparam - e, em certa medida, ajudaram a moldar - o reposicionamento de forças que se tornou pungente e irrefreável, a partir dos anos 1980, no campo mais amplo dos estudos sobre a história do pensamento e cultura política romana.

20 Em última instância, Momigliano derivou de uma crítica às convenções da historiografia constitucional um ataque à própria instituição/campo de saber, confusão esta que é um excelente exemplo de argumento non sequitur.

21 Para uma apresentação dessa (aparente) antítese vide: Sbriccoli, 2019.

22 Esse desafio não pertencia unicamente aos romanistas. A provocação foi lançada pelo medievalista Otto Brunner (Land und Herrschaft, 1939), bem como pela análise sociologizante de Carl Schmitt (Die Diktatur, 1921; Verfassungslehre, 1928). 
Em sua História da Constituição Romana (Storia della Costituzione Romana, 1951-1967), Martino seguia parcialmente o cânone da literatura jurídica quanto às reconstruçôes constitucionais. No entanto, ainda que concebesse a constituiçáo romana como um ordenamento jurídico particular, resultado da estabilização de princípios de governo. Para Martino a constituição não podia ser considerada "como um mero complexo de normas formais e estáticas, mas como uma realidade viva”, de modo que “[...] não é possível desenhar a magistratura republicana como um órgão legalmente determinado de modo estático e constante”, e sim na forma de uma história contada através dos costumes (mores maiorum), pela praxis constitucional, pelas leis das assembleias e pela intersecção com as demais instituiçóes políticas. Teria o próprio conceito de res publica na origem um valor semântico imanente ao patrimônio político-cultural existente, "a ideia mesma de poder se identificando com imagens e símbolos materiais" (MARTINO 1972-1975, I, p. 488-489, 494, respectivamente).

O nome do helenista Christian Meier foi notabilizado ao longo da segunda metade do século XX por sua colaboração ao projeto editorial idealizado em conjunto com Reinhart Koselleck, Werner Conze e Otto Brunner, marco na História dos Conceitos (Geschichtliche Grundbegriffe. Lexikon zur politisch-sozialen Sprache in Deutschland, 1972-1997), no mesmo ano em que o grupo de trabalho de história social em torno de Conze se reuniu na Universidade de Heidelberg para dar contornos iniciais ao projeto editorial que veio à lume a primeira obra de Meier. Fruto da $\mathrm{Ha}$ bilitationsschrift (1962) defendida em Frankfurt, foi intitulada Res Publica Amissa: Eine Studie zu Verfassung Geschichte der späten römischen Republik (1966). A obra foi reconhecida como uma lufada de ar fresco para a área acadêmica $^{23}$; e, embora tenha recebido mais atenção no ambiente de língua germânica, também teve seu valor reconhecido no ambiente anglófono por colocar nova luz sobre uma série de temas importantes para entender a gramática política dos romanos.

Como ocorreu com Martino, o emprego conceitual do termo "constituição" na obra de Meier soavam, em princípio, tradicionais na senda

23 A expressão (der frische Wind) foi retirada de uma resenha ao livro de Meier ([1966], 2007). Cf. Bleicken, 1968, p. 452. 
da história constitucional. Meier, todavia, insatisfeito com as limitaçóes da interpretação formalista do conceito operada pela Begriffsjurisprudenz, opôs os seus próprios. O conceito abstrato/normativo de "constituição" ou de "Estado" tal qual compreendidos pela tradição seria insuficiente para dar conta da reconstrução empírica e histórica de Roma que, na interpretação de Meier, melhor seria representada por termos como "realidade constitucional" (Verfassungswirklichkeit) e "gramática política" (MEIER, [1966] 2017, index s.v. Verfassung). A uma "constituiçáa”" no sentido conceitual-normativo e abstrato da tradição mommseniana, com suas regras e instituiçôes fixas, preferiu Meier se referir a uma "constituição de desenvolvimento" ou "orgânica”24 (gewachsene Verfassung), a qual, embora incluísse um núcleo mínimo de conteúdos constitucionais solidamente compartilhados, desconhecia amplo grau de objetivaçáo de suas instituiçóes, seus procedimentos e suas categorias. À expressão da "constituição não escrita", em seu implícito sentido de déficit, preferiu distinguir entre uma constituição organicamente formada, modelo que responderia pela experiência romana, e uma constituição "fundacional" (escrita ou não) que contém desde o princípio uma série de instituiçóes organizadas sistematicamente entre si, como no modelo das constituiçôes modernas. Para Meier, dever-se-ia interpretar essa aparente falta de completude ou perfeição técnicas não apenas pela possibilidade constante de choques no interior da civitas, mas, para além disso (e justamente por isso), o que tornava esse background institucional flexível. Evita-se pensar na constituição romana nos termos de uma estrutura estável e perene, mas como resultado dos sedimentos de um contínuo processo político somente concebido de modo preciso dentro das relaçóes políticas e sociais do mundo romano, de um lado, mas também pela dinâmica da formação e origem dos grupos e atores políticos.

A despeito de seus muitos méritos, não encontramos um arcabouço teórico para análise do mundo institucional romano em Martino e Meier, embora apontassem caminhos para levar a discussão adiante. Desde então, as principais obras de história constitucional incorporaram a análise da

24 O adjetivo "orgânico", emprego para a tradução de gewachsen (particípio do verbo wachsen, "crescer"), remete ao desenvolvimento natural/histórico do conjunto constitucional, mas não alude a uma concepção organicista da sociedade. 
cultura política mais ampla. A propensão à teorização e à discussão conceitual na historiografia recente se dá não por encantamento pela abstração meta-histórica, mas por aderência ao programa de investigaçóes comprometido com a reflexão sobre os instrumentos de análise mobilizados para a interpretação.

Os impulsos iniciais mais relevantes rumo a uma nova grade de delimitação conceitual foram oferecidos pelo historiador Jochen Bleicken na década seguinte. Mais apaziguadora com relação ao esforço da literatura conceitualista do século XIX, a obra de Bleicken reconheceu o desafio em solucionar a tensão entre um estudo das instituiçôes (i.e. uma análise "estática” ou sincrônica de certas unidades políticas em certo contexto) que não olvide do caráter histórico e fluído dessas mesmas instituiçôes e, em última instância, com a concreta prática política dos romanos (BLEICKEN, 1975).

Para Bleicken, o conceito "constituição" tem que ver com o ordenamento interno de uma comunidade política (die innere Ordnung eines Staates) ou com seu ordenamento constitucional (Verfassungsordnung) (BLEICKEN, [1975] 1985, p. 9, 119-121). O desenvolvimento do direito público na história romana demonstraria; porém, que, a despeito da importância que adquiriu, não assumiu o ius publicum em Roma, uma posição equiparável com aquela do direito moderno. Inexistindo em Roma a mesma bipartição burguesa-liberal entre Estado e sociedade da Modernidade, não havia uma entidade que pudesse ser representada com um direito seu e exclusivo, fundada por regras racionais estabelecidas na lei do soberano, mas um conjunto de normas legadas pelo hábito, pelo costume e pela história (überkommene Regeln) (BLEICKEN, [1975] 1985, p. 180).

O modelo institucional na análise de Bleicken teria surgido enquanto tal como fruto de um consenso construído ao longo do conflito das ordens a respeito do papel constitucional dos costumes (mos maiorum, consuetu$d o)^{25}$, das leis (leges) e do direito (ius $)^{26}$. Embora o historiador compartilhe

25 Para Bleicken ([1975] 1985, p. 182), o reino dos costumes (mos) abarca não apenas a práxis institucional do direito público entre os romanos (öffentliche Ordnung), mas também as regras morais de conduta (Sittenordnung).

26 Bleicken ([1975] 1985, p. 18I) descreve os três elementos como a soma das normas publicistas (die Summe der öffentlichen Regelsätze). Cf. Bleicken, 1975, p. 58-69, 347-354. 
com a tradição anterior à tripartição magistratura/Senado/populus como síntese institucional, o real núcleo do modelo de Bleicken, aquilo que garantiu certa unidade consensual e social, reside no convívio entre o vigor criativo da lei e a autoridade conservadora das práticas. Não só esses elementos possuíam origens distintas, mas também diferentes fontes de autoridade normativa, desde o direito entendido em sentido estrito até a ordem moral dos mores maiorum.

A constituição romana para Bleicken encontrava nesses instrumentos a chave para sua constante e, paradoxalmente, conservadora renovaçáo: normas eram introduzidas na República pela via das legislaçóes e plebiscitos (capazes de criar direitos e incorporá-los ao ius civitatis), assim como costumes mais recentes podiam ser invocados para suplementar/suplantar costumes caídos em desuso. Assumindo uma posição tacitiana (corruptissima re publica plurimae leges; marcada pela discordia, non mos, non ius) ${ }^{27}$, adequando-a ao seu modelo, para Bleicken a queda da República fora consequência justamente dos conflitos políticos que engendraram uma fissura irrecuperável na convivência entre lex, ius e mos. Não obstante, localizar precisamente na República tardia o núcleo das ideias constitucionais que até então regeram a cultura política romana e um conjunto de instituiçôes que nada tinha de estático (BLEICKEN, 1975, p. 432-439; BLEICKEN, [1975] 1985, p. 257-262).

A caixa de Pandora fora, por assim dizer, aberta, e não apenas para os estudiosos das instituiçóes romanas. Uma vez redefinidas as questōes, os métodos e a necessidade de reflexão teórica de base, foram alcançadas as condiçóes para uma reaproximação das análises jurídicas e das análises políticas e sociais, e sem que isso representasse (ou carecesse de) um retorno aos tempos de Mommsen. A historiografia jurídico-constitucional se tornou mais permeável às discussóes teórico-metodológicas realizadas nas villae vizinhas (especialmente a História dos Conceitos, a História da Linguagem Política e dos Discursos, temperadas pelas viradas linguística e cultural), e essa mesma abertura fez com que o resultado de suas investigações também passasse a interessar um grupo mais amplo para além de seus especialistas.

27 Segundo Tácito (Annales III, 27; III, 28), respectivamente: "Quanto mais corrompida a República, tanto mais leis"; "[...] discórdia, sem <observância> do costume e do direito". 
Como define Karl-Joachim Hölkeskamp, as obras recentes do mainstream da história do pensamento político compartilham de duas características fundamentais. Em primeiro lugar, convergem em uma abordagem integrativa de seus objetos de estudo, evitando retomar o fosso entre o plano das estruturas/formas e o plano dos eventos políticos. Respondendo de diferentes maneiras aos anseios das décadas anteriores, as pesquisas hodiernas tencionam fornecer interpretaçóes mais abrangentes e compreensivas de toda a estrutura institucional e cultural que dava ânimo ao mundo romano. Em decorrência desse objetivo, a nova direção do debate trouxe consigo uma constante preocupação com a formulação explícita das bases teóricas, dos aparatos instrumentais e pela busca de conceitos mais adequados para compreender a cultura político-jurídica dos romanos. Em segundo lugar, a atual agenda de pesquisas comportaria basicamente diferentes ângulos de visão sobre a formação da sociedade e tudo aquilo que, nesse ínterim, possui função constitutiva ou constitucional. Esse aspecto nomológico da cultura política da sociedade romana diz respeito não apenas ao objetivo contexto de convenções, códigos e valores que são partilhados intersubjetivamente pelos membros de uma sociedade, mas também, em um nível pré-expositivo e linguístico, o conjunto de significados encerrados na dimensão cognitiva ou expressiva da realidade social.

Ao final o que se extrai de tal aluvião é aquilo que Hölkeskamp (2010, p. 23) chama de "história constitucional estrutural", reconduzível metodologicamente aos conceitos de "descrição densa" (thick description) e "cultura” (definida por um viés semiótico/interpretativo) formulados pelo antropólogo cultural Clifford Geertz em A Interpretação das Culturas ([1973] 2019). Embora seja possível que as pesquisas considerem, como outrora, o conjunto daquelas instituiçóes, de normas e procedimentos como objeto de pesquisa, recusa-se a partir de uma concepção estanque de uma "constituição" romana como uma estrutura sistemática e estável, e sim como um contínuo processo concebido dentro das relaçóes políticas e culturais do mundo, de um lado, e também de seus esquemas simbólicos e culturais de significado político. Essas convicçóes gerais não implicam nem um holismo teórico ou em engessamento temático. O leque de escolhas metodológicas e de assuntos tratados é, pelo contrário, evidente, cabendo-nos aqui a apresentar um rol dessas variedades. 
Um primeiro conjunto é composto pelas pesquisas que mais diretamente respondem à tradição da historiografia novecentista; porém, após as guinadas interpretativas mencionadas. Essas obras ora enfatizam a história constitucional como um panorama de instituiçóes relacionadas entre si, ora esmiúçam determinados institutos ou práticas constitucionais. Tomemos por exemplos dessa renovação as obras de Andrew Lintott, especialmente The Constitution of the Roman Republic (1999); de Callie Williamson, The Laws of the Roman People (2005); e de Luigi Capogrossi Colognesi, o manual Storia di Roma tra diritto e potere (2014). De um lado, seus leitores encontrarão as mesmas discussões que foram iniciadas por Niebuhr e Mommsen, na forma de uma história da arquitetura institucional de Roma e de suas regras ${ }^{28}$, ou a respeito do desenvolvimento particular de certas instituiçóes ${ }^{29}$; por outro lado, trata-se de fornecer uma história que leve em conta as relaçóes concretas entre o disciplinamento normativo e as práticas concretas, uma narrativa da "costituzione nel suo farsi" (COLOGNESI, 2014, p. 10) que, como defende Lintott (1999, p. 16), não é útil apenas à historiografia institucional, pois "[...] a proper understanding of constitutional norms is a safeguard against anachronistic political judgments". É ainda visível, especialmente na última década, a multiplicação de trabalhos histórico-jurídicos e constitucionais que se filiam explicitamente ao Law and Society Studies ${ }^{30}$.

Um segundo grupo de pesquisas que, à semelhança do primeiro, parte de certa tradição literária na direção dos novos ventos teórico-metodológicos, é a historiografia do pensamento político propriamente dita. Em diálogo com a nova história constitucional, as pesquisas recentes levam em conta o universo de significados das práticas políticas e filosóficas romanas, excluindo o ranço novecentista quanto à pretensa falta de originalidade ou qualidade do pensamento romano. Como explica Dean Hammer (2014. p. 5): "[...] the Roman struggle to make sense of their political world gives us

28 De amplo escopo, cite-se: Bretone, 1982; Wieacker, 1988, 2006; Brund, 1988; Lintott, 1999; Colognesi, 2014; Rainer, 2006; Pani, 20 I0; Hölkeskamp, 2020.

29 Quanto a pesquisas que enfocam determinados institutos, cite-se: Brennan, 2002; Smith, 2006; Beck et al. 2011; Polo, 2011; Touri, 2016.

30 Para essa nova história constitucional-jurídica: Du Plessis, 2013, 2016; Du Plessis, Ando e Touri, 2016; Du Plessis e Cairns, 2007. 
insight into what it meant for them, and can mean for us, to be political beings". Essa abordagem contextual e semiótica permitiu, por um lado, a reavaliação do lugar de escritores romanos seja na própria história do pensamento romano ${ }^{31}$, seja na historiografia a respeito de sua recepçáo e readequação na Idade Média e nos primórdios da Idade Moderna ${ }^{32}$. São particularmente exemplificativos os livros pioneiros Le pain et le cirque (1984), de Paul Veyne, e Intellectual Life in the Late Roman Republic (1985), de Elizabeth Rawson; os trabalhos de Dean Hammer, especialmente Roman Political Thought (2014), e os mais recentes Il pensiero politico romano (2018), de Giuseppe Zecchini, e Roman Political Thought (2018), de Jed Atkins.

Podemos agrupar, em um terceiro escopo, aqueles trabalhos que enfatizam os fundamentos da cultura política e jurídica do mundo romano. $\mathrm{O}$ conceito de cultura política engloba, nesse ponto, duas dimensóes: uma ligada às formas simbólicas, à estrutura de linguagem e ao ambiente discursivo-comunicativo; e outra ligada às práticas políticas. A primeira contém as dimensóes simbólicas que, sedimentadas na gramática cultural e política $^{33}$, permanentemente renovam a legitimidade e fornecem condiçóes de possibilidade a tudo aquilo que faz parte da segunda dimensão, mais eminentemente técnica, explícita, ligada às agendas políticas concretas, à formação dos grupos políticos, à história das ideologias e, ainda, aos jogos de conquista e manutenção de poder ${ }^{34}$.

Dentre esse leque de pesquisa, consideramos oportuno salientar uma crescente e recente bibliografia a respeito do constitucionalismo romano, um tanto quanto prática como matiz de pensamento e chave interpretativa para análise da Roma republicana ${ }^{35}$. Tais autores buscam reavivar, no debate, a reflexão a respeito das contribuiçóes distintas que as instituiçóes

31 Destacamos nesse grupo: Wood, 1988; Powel, 200I; Steel, 2005, 2013; Harries, 2006; Connolly, 20I5; Kapust, 2011; Wilkinson, 2012; Atkins, 2013, 2018; Fezzi, 2015; Vasaly, 2015; Du Plessis, 2016; Du Plessis, Ando e Touri, 2016.

32 Pioneiro e pouco lembrado: Gimore, 1967. Cite-se ainda: Millaar, 2002; Hammer, 2008; Touri, 2007.

33 Voltados à cultura política, vide: Moatti, 1997, 20 I8; Flower, 20 I0; Ando, 20 I I, 20 15; Hölkeskamp, 20 I0, 2017; Hodgson, 2017; Gargola, 2017.

34 Quanto às questões da praxis política, remetemos para: Saller, 1995; Frier, 1985; Morstein-Marx, 2004; Arena, 2013.

35 Focados no pensamento constitucional, cite-se: Lobrano, 1996; Pani, 2010; Straumann, 2016; Lee, 2016; Alba, 2019; Atkins, 2019, p. II-36; Osle, 2019. 
republicanas e o pensamento romano legaram a partir de um conceito amplo de "constitucionalismo". De um modo geral, seus cultores apontam que mesmo em pleno roman revival permanece predominante na literatura uma grande obscuridade a respeito do assunto. Isso se daria, em primeiro lugar, pelo prestígio que o pensamento político grego ainda goza entre os teóricos políticos e historiadores do pensamento. Em segundo lugar, a recorrente etiqueta do "republicanismo clássico" - pautada na clássica distinção de Constant entre a liberdade dos antigos e dos modernos - também engessa constantemente a discussão ao obscurecer os instrumentos conceituais tipicamente romanos.

A síntese do estado da arte se encontra em um livro que tem chamado a atençáo dos resenhistas da área: Crisis and Constitutionalism (2016) do suíço Benjamin Straumann. No mesmo ano, Daniel Lee explorou as raízes romanas do pensamento político medieval e da Primeira Modernidade no livro Popular Sovereignty in Early Modern Constitutional Thought. Em sua obra, Straumann argumenta que o pensamento romano de fato deveria ser destacado pelos intérpretes por sua visão da política centrada na existência de certos direitos (iura) e normas garantidoras da ordem institucional da civitas. Tal pensamento constitucional não inclui apenas um modo teorético de ordenar a realidade social, mas também pressupóe uma teoria política normativa a respeito das fontes constituintes da ordem jurídica e dos limites impostos aos cidadáos para a mantença dessa ordem. O trabalho de Lee (2016), por sua vez, guardou particular cuidado para os modos como as ideias registradas na pena de jurisconsultos romanos, habilmente (re)contextualizadas no medievo, puderam servir de medium para a forja das teorias modernas da autoridade legítima e da soberania popular. Em arremate, os pesquisadores a respeito do constitucionalismo romano parecem concordar que "[...] institutions matter, but they presuppose constitutionalism. Constitutionalism is pivotal, but it presupposes a particular political theory" (STRAUMANN, 2016, p. 12).

\section{Considerações finais: as linhas de força da historiografia romanista contemporânea}

Por caminhos distintos, a história do pensamento político e a história do direito passaram, nos últimos trinta anos, a acessar com atenção 
renovada os escritores e a realidade institucional da Roma republicana. Acadêmicos dos dois campos disciplinares insurgiram-se contra perspectivas que, alinhavadas no século XIX, tornam-se ortodoxias e lugares-comuns no começo do século seguinte. Essas ortodoxias possuem suas peculiaridades, isso é inegável, mas tentamos argumentar que possuem paralelismos em termos epistemológicos e, ainda mais importante, a indisposição de certos acadêmicos com suas premissas e recomendaçóes acaba os aproximando (em termos epistemológicos e substantivos) desde nas últimas décadas $\mathrm{O}$ interesse renovado por Roma, por seu pensamento e pela sua engenharia institucional deve ser inscrito no bojo de uma renovada compreensão sobre como deve se proceder ao escrutínio do passado.

$\mathrm{Na}$ primeira seção, viu-se que a historiografia do pensamento político encontrou, entre os historiadores de Cambridge, um dos argumentos mais poderosos para lidar com as ideias do passado em termos inovadores, insurgindo-se contra uma história das ideias calcada exclusivamente na interpretação exegética dos textos. Alegavam esses historiadores que nada havia de histórico e pouco se acrescentaria à compreensão do passado retirar os textos de seus contextos, assumindo-se que a verdadeira interpretaçáo estava encerrada nas obras do passado e que poderia ser acessada apenas por uma leitura cuidadosa e sistemática da economia interna dos textos. Como defendido por Quentin Skinner, uma genuína história das ideias políticas deveria localizar as invectivas dos pensadores em seu contexto - sobretudo intelectual, mas também social e político - para efeitos de compreendê-las adequadamente. Uma tarefa hermenêutica que passou a ser executada por aqueles pensadores em locus preferencial: as ideias políticas do início da modernidade. Identificou-se, então, uma tradição política que, apesar de estar intimamente relacionada à forja do pensamento político moderno, havia sido esquecida desde o século XIX. Seja ela nomeada neorromana ou republicana, assume-se que sua origem está em Roma, em suas ideias e instituições.

É certo que, desde Políbio a constituição romana ocupa papel central no pensamento romano. Como acreditamos ter apresentado, Cícero e Lívio dedicaram muita atençáo à constituição da cidade, um dos pontos mais relevantes nas suas obras, interpretadas na primeira seção deste trabalho. 
Se do ponto de vista da história das ideias a tarefa hermenêutica se apresenta como investigar de que forma a ideia de constituição mista-balanceada pode ser lida contextualmente, a compreendendo como um elemento de uma gramática peculiar a ser mobilizada, torna-se factível compreender o que os autores romanos estavam fazendo ao refletirem sobre o assunto. Essa tradição "redescoberta" inicialmente impulsionou as obras dos teóricos e historiadores ligados ao republicanismo contemporâneo; mas, desde entáo, o interesse pelo pensamento romano passou a ser compartilhado por um número maior de historiadores, classicistas, filósofos e politólogos. Munidos de um aparato epistemológico específico, autores contemporâneos que aqui foram considerados como responsáveis por um roman turn na teoria política (re-)assumiram esse aspecto da história de Roma como locus de investigação. $\mathrm{O}$ pensamento político e as instituiçóes romanas deixaram de ser considerados apenas como origem de uma tradição posterior, e passaram a ser o próprio objeto de análise. Esse esforço encontra-se com movimento similar identificável no âmbito da história do direito com a emergência de uma série de estudos sobre as instituições romanas, como que em um movimento de renovação metodológica paralelo àquele realizado na história das ideias.

$\mathrm{Na}$ segunda seção, viu-se que, do ponto de vista jurídico, a crítica às teses tradicionais insurgiu-se contra a ortodoxia que compreendia as instituiçóes romanas desencarnadas da história, como se um mero esquema entre diversas magistraturas e assembleias, descurando do contexto de significados intersubjetivamente compartilhados em que essas instituiçôes funcionavam. Se aos autores do século XIX se pode dar o crédito de investigar minuciosamente as fontes para oferecer reconstruçóes do funcionamento institucional, juristas e historiadores a partir da metade do século XX passaram a exigir maior rigor nos parâmetros de contenção do anacronismo.

Há, portanto, um tema em comum para grande parte dos historiadores, juristas e teóricos debruçados nas pesquisas mais recentes sobre a comunidade política da Roma republicana: sua realidade constitucional. Esse interesse temático, que já é amplo em si mesmo, comporta grande variedade de abordagens, de critérios heurísticos e de usos conceituais, mas 
pressupóe uma diretriz metodológica comum. Para as pesquisas recentes, a "constituição" dos romanos é entendida não apenas como conjunto de normas, instituiçóes e práticas que regiam a vida da res publica, mas também como significados reiterados, hábitos mentais, convenções linguísticas e particularidades culturais indissociavelmente ligados a essas instituiçôes. Também é partilhada a constatação de que as análises da constituição da comunidade política romana fornecerão apenas uma imagem aproximativa e inescapavelmente incompleta daquela realidade. O rigor da compreensáo histórica deve dar-se, então, pela escolha criteriosa de chaves conceituais e métodos empregados. Em termos inspirados por Geertz, a reconstituição daquele universo simbólico apenas pode ser alcançada através de uma interpretação densa.

\section{Referências}

ALBA, J. M. R. Constitucionalismo Romano. Madrid: Tecnos, 2019.

ALFÖLDY, G. A História Social de Roma. Lisboa: Presença, 1989.

ANDO, C. Law, language, and empire in the Roman tradition. Philadelphia: UPP, 2011.

ANDO, C. Roman social imaginaries. Toronto: UTP, 2015.

ARENA, V. Libertas and the Practice of Politics in the Late Roman Republic. Oxford: OUP, 2013.

ASMIS, E. The State as a Partnership: Cicero's Definition of Res Publica in his work On The State. History of Political Thought, n. 25, 2004. Disponível em: https://bit.ly/3k9WX5A. Acesso em: 8 nov. 2020.

ATKINS, J. Cicero on Politics and the Limits of Reason. New York: CUP, 2013.

ATKINS, J. Roman Political Thought. Cambridge: CUP, 2018.

BECK, H.; DUPLÁ, A.; JEHNE, A.; POLO, F. P. Consuls and res publica. Cambridge: CUP, 2011.

BLEICKEN, J. Rezension zu Christian Meier, Res Publica Amissa. Zeitschrift für Rechtsgeschichte, v. 85, n. 1, 1968. Disponível em: https://bit.ly/3gGsydd. Acesso em: 30 ago. 2020.

BLEICKEN, J. Lex Publica. Gesetz und Recht in der römischen Republik. Berlin: Gruyter, 1975.

BLEICKEN, J. [1975]. Die Verfassung der Römischen Republik. 4. ed. München: UTB, 1985.

BÖCKENFÖRDE, E.-W. História da Filosofia do Direito e do Estado. Porto Alegre: Fabris, 2012 . 
BRENNAN, T. C. The Praetorship in the Roman Republic. 2. vol. Oxford: OUP, 2000.

BRUNT, P. A. The Fall of the Roman Republic and Related Essays. Oxford: Clarendon, 1988.

CÍCERO. Tratado da República. Tradução de Francisco de Oliveira. Lisboa: Temas e Debates, 2008.

BERLIN, I. Estudos sobre a humanidade. São Paulo: Cia das Letras, 2002.

BESSON, S.; MARTI, J. L. (ed.). Law and Republicanism. Oxford: OUP, 2009.

BRETONE, M. Tecniche e ideologie dei giuristi romani. 2. ed. Napoli: ESI, 1982.

COLOGNESI, L Capogrossi. Storia di Roma tra diritto e potere. 2. ed. Bologna: il Mulino, 2014.

CONNOLLY, J. The State of the Speech. Princeton: PUP, 2007.

CONNOLLY, J. The Life of Roman Republicanism. Princeton: PUP, 2015.

CORNELL, T. J. Cicero on the Origins of Rome. In: POWELL, J. G. F.; NORTH, J. A. Cicero's

Republic: Bulletin of the Institute of Classical Studies (BICS Supplement 76). [S. l.]: 2001. p. 41-56.

DU PLESSIS, P. J. (ed.). New Frontiers: Law and Society in the Roman World. Edinburgh: EUP, 2013.

DU PLESSIS, P. J. (ed.). Cicero's Law: Rethinking Roman Law of the Late Republic. Edinburgh: EUP, 2016.

DU PLESSIS, P. J.; ANDO, C.; TUORI, K. (ed.). The Oxford Handbook of Roman Law and Society. Oxford: OUP, 2016.

DU PLESSIS, P. J.; CAIRNS, J. W. Beyond Dogmatics: Law and Society in the Roman World. Edinburg: EUP, 2007.

FEZZI, L. Modelli politici di Roma Antica. Roma: Carocci, 2015.

FLOWER, H. I. The Roman Republics. Princeton: PUP, 2010.

FRIER, B. W. The Rise of the Roman Jurists. Princeton: PUP, 1985.

GARGOLA, D. J. The Shape of the Roman Order. Chapel Hill: UNCP, 2017.

GEERTZ, C. A Interpretaçáo das Culturas. Rio de Janeiro: LTC, 2019.

GIERKE, O. von. Die historische Rechtsschule und die Germanisten. Berlin: Schade, 1903.

GILMORE, M. Argument from Roman Law in Political Thought, 1200-1600. New York: Russell \& Russell, 1941.

HABERMAS, J. Human rights and popular sovereignty: the liberal and republican versions. Ratio Juris, v. 7, 1994. Disponível em: https://bit.ly/2QD8nlV. Acesso em: 30 ago. 2020. 
Em termos romanos: Res publica, história e constituição na historiografia do pensamento político e na historiografia institucional contemporâneas | Márlio Aguiar Tiago Bahia Losso

HAMMER, D. Roman Political Thought and the Modern Theoretical Imagination. Norman: Oklahoma UP, 2008.

HAMMER, D. Roman Political Thought from Cicero to Augustine. Cambridge: CUP, 2014.

HARRIES, J. Cicero and the Jurists. London: Duckworth, 2006.

HODGSON, L. Res publica and the Roman Republic: "Without Body or Form”. Oxford: OUP, 2017.

HÖLKESKAMP, K.-J. Reconstructing the Roman Republic: An Ancient Political Culture and Modern Research. Princeton: PUP, 2010.

HÖLKESKAMP, K.-J. Libera res publica. Die politische Kultur des antiken Rom. München: Verlag, 2017.

HÖLKESKAMP, K.-J. Roman Political Reflections: Studies in Politics, Power, and Pageantry. München: Verlag, 2020.

IGGERS, G. G. The German Conception of History. Middletown: WUP, 1983.

KAPUST, D. Skinner, Pettit, and Livy: The Conflict of the Orders and the Ambiguity of Republican Liberty. History of Political Thought, v. 25, n. 3, p. 377-401, 2004.

KAPUST, D. Republicanism, Rhetoric and Roman Political Thought: Sallust, Livy, and Tacitus. New York: CUP, 2011.

KAPUST, D. 'Ecce Romani!': Invited Review Essay on Recent Scholarship on Roman Political Thought. Political Theory, v. 45, n. 5, p. 705-719, 2017.

LABORD, C.; MAYNOR J. M. (ed.). Republicanism and Political Theory. New York: Blackwell, 2008.

LEE, D. Popular Sovereignty in Early Modern Constitutional Thought. Oxford: Oxford University Press, 2016.

LINTOTT, A. The Constitution of the Roman Republic. Oxford: Clarendon, 1999.

LIVIO, T. História de Roma. Tradução de Paulo Matos Peixoto. São Paulo: Paumape, 1989.

LOBRANO, G. Res publica res populi: la legge e la limitazione del potere. Torino: Giapiccheli, 1996.

MARTINO, F. de. Storia della costituzione romana.6 vol. 2. ed. Napoli: Jovene, 1972-1975.

MCCORMICK, J. Machiavellian Democracy. New York: CUP, 2011.

MCGING, B. Polybius' Histories. New York: OUP, 2010.

MEIER, C. [1966]. Res publica amissa. Eine Studie zu Verfassung und Geschichte der späten römischen Republik. 4. ed. München: Verlag, 2017. 
MILLAR, F. The Roman Republic in Political Thought. London: BUP, 2002.

MOATTI, C. La Raison de Rome: Naissance de l'esprit critique à la fin de la République. Paris: Seuil, 1997.

MOATTI, C. Res Publica: Histoire romaine de la chose publique. Paris: Fayard, 2018.

MOMIGLIANO, A. Reviewed Work Römischer Staat und Staatsgedanke by Ernst Meyer. Journal of Roman Studies, v. 39, 1949. Disponível em: https://bit.ly/2YNeOax. Acesso em: 30 ago. 2020.

MOMIGLIANO, A. Le conseguenze del rinnovamento della storia dei diritti antichi. In: OLSCHKI, L. S. La storia del diritto nel quadro delle scienze storiche. Firenze: Olschinki, 1966.

MOMMSEN, T. Römische Staatsrecht. 5 vol. Leipzig: Hirzel, 1871-1888.

MORSTEIN-MARX, R. Mass Oratory and Political Power in the Late Roman Republic. Cambridge: CUP, 2004.

MURKENS, J. E. K. The Future of Staatsrecht. The Modern Law Review, v. 70, n. 5, 2007. Disponível em: https://bit.ly/3bdnyLS. Acesso em: 30 ago. 2020.

OSLE, Rafael Domingo. Direito Romano e Constitucionalismo Global. Novos Estudos Jurídicos, v. 24, n. 2, 2019. Disponível em: https://bit.ly/32GXXaq. Acesso em: 30 ago. 2020.

PANI, M. Il Costituzionalismo di Roma Antica. Bari: Laterza, 2010.

PETTIT, P. Republicanism: A Theory of Freedom and Government. Oxford: OUP, 1997.

PETTIT, P. On the people's terms: a republican theory and model of democracy. New York: CUP, 2012 .

PETTIT, P. Self-defense on Five Fronts: A Reply to My Commentators. In: DERPMANN, S.; SCHWEIKARD, David P. (eds.). Philip Pettit: Five Themes from his Work. London: Springer, 2016. p. 135-164.

PINZANI, A. Republicanismo(s), Democracia e Poder. Veritas, v. 52, p. 5-14, 2007.

POLIBIOS. História. Tradução de Mário da Gama Kury. Brasília: UNB, 1985.

POLO, F. P. The Consul at Rome: The Civil Functions of the Consuls in the Roman Republic. Cambridge: CUP, 2011.

POWELL, J. G. F. Were Cicero's Laws the Laws of Cicero's Republic? In: POWELL, J. G. F.; NORTH, J. A. Cicero's Republic: Bulletin of the Institute of Classical Studies (BICS Supplement 76). [S. l.]: 2001. p. 17-39.

RAINER, J. M. Römisches Staatsrecht. Darmstadt: WBG, 2006.

SALLER, R. P. Personal Patronage under the Early Empire. Cambridge: CUP, 1982.

SCHOFIELD, M. Cicero's definition of res publica. In: POWELL, J. (ed). Cicero the philosopher. Oxford: Clarendon, 1995. p. 63-83. 
Em termos romanos: Res publica, história e constituição na historiografia do pensamento político e na historiografia institucional contemporâneas | Márlio Aguiar Tiago Bahia Losso

SEBASTIANI, B. B. Bélica Liçáa Polibiana. Orientadora: Maria Luiza Corassin. 2006. Tese (Doutorado em História Social) - Programa de Pós-Graduação em História Social, Universidade de São Paulo, São Paulo, 2006.

SBRICCOLI, M. História do Direito e História da Sociedade. Seqüência, v. 40, n. 82, 2019. Disponível em: https://bit.ly/34Lyq2D. Acesso em: 30 ago. 2020.

SILVA, R. História Intelectual e Teoria Política. Revista de Sociologia e Ciência Política, v. 17, n. 34, p. 301-318, 2009.

SKINNER, Q. As fundaçóes do pensamento político moderno. São Paulo: Cia das Letras, 1996.

SKINNER, Q. Liberdade antes do Liberalismo. São Paulo: UNESP, 1999.

SKINNER, Q.; BOURKE, R. (ed.). Popular Sovereignty in Historical Perspective. Cambridge: CUP, 2016.

SMITH, C. J. The Roman Clan. Cambridge: CUP, 2006.

STEEL, C Reading Cicero: Genre and Performance in Late Republican Rome. London: Duckworth, 2005.

STEEL, C. Community and Communication: Oratory and Politics in Republican Rome. Oxford: OUP, 2013.

STRAUMANN, B. Crisis and Constitutionalism: Roman Political Thought from the Fall of Rome to the Age of Revolution. Oxford: OUP, 2016.

SYME, R. The Roman Revolution. Oxford: Clarendon, 1939.

TUORI, K. Ancient Roman Lawyers and Modern Legal Ideals. 2. ed. Frankfurt am Main: Klostermann, 2007.

TUORI, K. The Emperor of Law: The Emergence of Roman Imperial Adjudication. Oxford: OUP, 2016.

URBINATI, N. Competing for liberty: the republican critique of democracy. Political Theory, v. 106, n. 3, 2012. Disponível: https://bit.ly/3gJReld. Acesso em: 30 ago. 2020.

VASALY, A. Livy's Political Philosophy. Cambridge: CUP, 2015.

VIROLI, M. Republicanism. New York: F. S. Giroux, 2002.

WALBANK, F.W. Polybius, Rome and the Hellenistic World. New York: CUP, 2002.

WOOD, N. Cicero's Social and Political Thought. Berkeley: UCP, 1988.

WIEACKER, F. [1988]. Römische Rechtsgeschichte. 2 vol. München: Beck, 2006.

WIEACKER, F. História do Direito Privado Moderno. 4. ed. Lisboa: Calouste Gulbenkian, 2010 . 
WILLIAMSON, C. The Laws of the Roman People: Public Law in the Expansion and Decline of the Roman Republic. Ann Arbor: Michigan Press, 2008.

WILKINSON, J. Republicanism during the Early Roman Empire. New York: Continuum, 2012.

ZECCHINI, G. Il pensiero politico romano. Roma: Carocci, 2018.

Recebido em 08/11/2020

Aprovado em 01/02/2021 


\section{On Romans' terms: Res publica, history and constitution in the history of political thought and contemporary institutional history}

\section{Abstract}

Since neo-republicanism included Roman thinkers and their modern readers among the relevant sources for the debate within Political Theory, there has been a renewed interest in Roman sources as elements to enrich the contemporary debate on political theory and also to re-evaluate Roman influence among moderns. If at first its authors emphasized the Roman contribution to modern political traditions, in recent years an arguably vast production focused on the political thinking of the Romans themselves, what we call the "roman turn". This article aims to contextualize and outline the methodological characteristics of this "Roman turn". To this end, the text is divided into two sections: the first analyses the historiography of political thought itself, after the impulse of Cambridge School contextualism; the second section is devoted to the legal history and, more specifically, to the recent directions of institutional or constitutional historiography.

Keywords: Institutional History. History of Ideas. Theory and History of Historiography. 